|| ISSN(online): 2589-8698 || ISSN(print): 2589-868X ||

International Journal of Medical and Biomedical Studies

Available Online at www.ijmbs.info

NLM (National Library of Medicine ID: 101738825)

Index Copernicus Value 2019: 79.34

Original Research Article

Volume 5, Issue 7; July: 2021; Page No. 65-68

\title{
PATTERN OF MYOCARDIAL FIBROSIS IN ISCHEMIC AND NON ISCHEMIC CARDIOMYOPATHY
}

\section{Dr Chaman Lal Kaushal ${ }^{1}$, Dr Danquale Vance Kynshikhar ${ }^{2}$, Dr Anupam Jhobta ${ }^{3}$, Dimple Kaushal ${ }^{4}$}

${ }^{1}$ Resident, Dept. of Radiodiagnosis, IGMC, Shimla, HP, India

${ }^{2}$ Resident, Dept. of Radiodiagnosis, IGMC, Shimla, HP, India

${ }^{3}$ Professor, Dept. of Radiodiagnosis, IGMC, Shimla, HP, India

${ }^{4}$ MSc(Agriculture) Molecular biology and biotechnology, GBPUA\&T, Pantnagar, Uttarakhand, India.

Article Info: Received 08 May 2021; Accepted 03 July 2021

DOI: https://doi.org/10.32553/ijmbs.v5i7.2021

Corresponding author: Dr Danquale Vance Kynshikhar

Conflict of interest: No conflict of interest.

\begin{abstract} dilatation and are due to variety of causes that frequently are genetic. echocardiography evaluated in department of cardiology at IGMC, Shimla over a period of one year.

Demographics:

$\begin{array}{llll}\text { Demographics } & \text { Overall Group } & \text { Male } & \text { Female } \\ \text { Mean Age (year ) } \pm \text { SD } & 53.86 \pm 16.34 & 54.45 \pm 19.41 & 53.94 \pm 16.36 \\ \text { Gender (n) } & 38 & 17(44.73 \%) & 21(55.26 \%)\end{array}$
\end{abstract}

Background: The cardiomyopathies are defined as "heterogenous group of diseases of the myocardium associated with mechanical or electrical dysfunction that usually (but not invariably) exhibit inappropriate ventricular hypertrophy or

Methods: The cross sectional hospital based study was conducted in the Department of Radiodiagnosis in patients with heart failure with LVEF (Left Ventricular Ejection Fraction) of <45\% without RWM (Regional Wall Motion) abnormality on

Results: Myocardial fibrosis was seen in $4(100 \%)$ patients of ischemic cardiomyopathy and 3 (18.75\%) patients of non ischemic cardiomyopathy with significant $P$ value of 0.01 and odd ratio of 1.67 . The subendocardial myocardial fibrosis was seen in $3(75 \%)$ patients of ischemic cardiomyopathy while it was not seen in non ischemic cardiomyopathy with significant $\mathrm{P}$ value of $<0.01$ and odd ratio of 3.59 .

Conclusion: Cardiac MRI has important role in dilated cardiomyopathies for distinguishing ischemic and non ischemic types as well as in evaluation of various etiological types.

Keywords: MRI, Myocardial, Cardiomyopathies

\section{Introduction}

The cardiomyopathies are defined as "heterogenous group of diseases of the myocardium associated with mechanical or electrical dysfunction that usually (but not invariably) exhibit inappropriate ventricular hypertrophy or dilatation and are due to variety of causes that frequently are genetic." '1 In general cardiomyopathies are myocardial diseases associated with cardiac dysfunction.

The etiologies of cardiomyopathies are conventionally divided into primary and secondary causes. The primary cardiomyopathies solely involve heart and are intrinsic to myocardium. The secondary cardiomyopathies are those which are part of multiorgan involvement. "The 2006 American Heart Association" classified the primary cardiomyopathies as genetic type, acquired type and mixed type. The genetic type of cardiomyopathies includes Hypertrophic cardiomyopathy, Arrhythmogenic right ventricular dysplasia, Left ventricular non compaction and various Storage diseases. The acquired type include inflammatory (myocarditis), stressed provoked or peripartum cardiomyopathies. The mixed type of cardiomyopathies includes dilated cardiomyopathies and restrictive cardiomyopathies. The secondary cardiomyopathies includes various multisystemic disease like amyloidosis, sarcoidosis, hypertension, diabetes mellitus, hemochromatosis, hypothyroidism, hyperthyroidism, drug induced (anthracyclines) etc. ${ }^{2}$

\section{Material and methods}

Study design and patient population and sample size: The cross sectional hospital based study was conducted in the Department of Radiodiagnosis in patients with heart failure with LVEF (Left Ventricular Ejection Fraction) of $<45 \%$ without RWM (Regional Wall Motion) abnormality on echocardiography evaluated in department of cardiology at IGMC, Shimla over a period of one year. Coronary angiography was done in all eligible patient of dilated cardiomyopathy in the department of Cardiology and CT coronary angiography was planned in patients where coronary angiography was not possible in the department of Radiodiagnosis IGMC, Shimla. The Radiologist who reported the cardiac MRI was blinded to the result of coronary angiography/CT coronary angiography. Comparison of cardiac MRI and coronary angiography was 
made in the end of the study to find out the accuracy of cardiac MRI in the diagnosis of ischemic cardiomyopathies and differentiating it from the non ischemic cardiomyopathies. Thereafter association between pattern of distribution of myocardial fibrosis with ischemic and non ischemic Cardiomyopathy was made.

Every consecutive eligible patient was enrolled for the study and the research procedure was in accordance with the approved ethical standards of Indira Gandhi Medical College and Hospital, Shimla, Ethics Committee.

\section{Exclusion Criteria:}

- Patients having contraindication for MRI e.g. Pacemaker, Metallic implants.
- Patients with deranged renal function test with e GFR $<15 \mathrm{ml} / \mathrm{kg} /$ minute

- Patients with documented myocardial infarction.

- Patients with hypersensitivity to Gadolinium.

\section{Data Analysis:}

Data was reported as counts and percentages for categorical variables and mean $\pm \mathrm{SD}$ for continuous variables. The association of pattern and distribution of myocardial fibrosis with ischemic cardiomyopathy was analyzed calculating odds ratio and $95 \%$ C.I. The statistical analysis was done using Epi info version 7 software. Two sided $p$ value of $<0.05$ was taken as statistically significant.

Result: Table no.-1: Pattern of distribution of myocardial fibrosis in ischemic and non ischemic cardiomyopathy

\begin{tabular}{|c|c|c|c|c|c|}
\hline & & $\operatorname{ICM}(n=4)$ & $\operatorname{NICM}(n=16)$ & OR & P VALUE \\
\hline \multirow{2}{*}{ MYOCARDIAL FIBROSIS } & YES & $4(100 \%)$ & $3(18.75 \%)$ & \multirow[t]{2}{*}{1.67} & \multirow[t]{2}{*}{0.01} \\
\hline & NO & 0 & $13(81.25 \%)$ & & \\
\hline \multirow[t]{2}{*}{ SUBENDOCARDIAL CT } & YES & $3(75 \%)$ & 0 & \multirow[t]{2}{*}{3.59} & \multirow[t]{2}{*}{$<0.01$} \\
\hline & NO & $1(25 \%)$ & $16(100 \%)$ & & \\
\hline \multirow[t]{2}{*}{ SUBENDOCARDIAL NCT } & YES & 0 & 0 & \multirow[t]{2}{*}{ - } & \multirow[t]{2}{*}{-} \\
\hline & NO & $4(100 \%)$ & $16(100 \%)$ & & \\
\hline \multirow[t]{2}{*}{ TRANSMURAL CT } & YES & $2(50 \%)$ & 0 & \multirow[t]{2}{*}{1.3} & \multirow[t]{2}{*}{0.03} \\
\hline & $\mathrm{NO}$ & $2(50 \%)$ & $16(100 \%)$ & & \\
\hline \multirow[t]{2}{*}{ TRANSMURAL NCT } & YES & 0 & $2(12.50 \%)$ & \multirow[t]{2}{*}{0.00} & \multirow[t]{2}{*}{1.0} \\
\hline & NO & $4(100 \%)$ & $14(87.50 \%)$ & & \\
\hline \multirow{2}{*}{$\begin{array}{lll}\text { FIBROSIS } & \text { IN } & \text { CORONARY } \\
\text { TERRITORY } & & \\
\end{array}$} & YES & $4(100 \%)$ & 0 & \multirow[t]{2}{*}{9.09} & \multirow[t]{2}{*}{$<0.01$} \\
\hline & $\mathrm{NO}$ & 0 & $16(100 \%)$ & & \\
\hline \multirow[t]{2}{*}{ MIDMYOCARDIAL } & YES & 0 & 0 & \multirow[t]{2}{*}{-} & \multirow[t]{2}{*}{-} \\
\hline & NO & $4(100 \%)$ & $16(100 \%)$ & & \\
\hline \multirow[t]{2}{*}{ EPICARDIAL } & YES & 0 & 0 & - & - \\
\hline & NO & $4(100 \%)$ & $16(100 \%)$ & & \\
\hline FOCAL PATCHY & YES & 0 & $1(6.25 \%)$ & \multirow[t]{2}{*}{0.00} & \multirow[t]{2}{*}{1.00} \\
\hline & $\mathrm{NO}$ & $4(100 \%)$ & $15(93.75 \%)$ & & \\
\hline
\end{tabular}

CT-Coronary Territory, NCT-Non Coronary Territory, ICM-Ischemic Cardiomyopathy, NICM-Non Ischemic cardiomyopathy, OR-Odd Ratio,

In our study conventional angiography was done in 20 patients. Out of these 4 patients were of ischemic cardiomyopathy and 16 were of non ischemic cardiomyopathy. The association of pattern of myocardial fibrosis with ischemic and non ischemic cardiomyopathy was done in these patients.

- Myocardial fibrosis was seen in $4(100 \%)$ patients of ischemic cardiomyopathy and $3(18.75 \%)$ patients of non ischemic cardiomyopathy with significant $P$ value of 0.01 and odd ratio of 1.67 .

- The subendocardial myocardial fibrosis was seen in 3 (75\%) patients of ischemic cardiomyopathy while it was not seen in non ischemic cardiomyopathy with significant $\mathrm{P}$ value of $<0.01$ and odd ratio of 3.59 .

- The myocardial fibrosis in coronary territory was seen in $4(100 \%)$ patients of ischemic cardiomyopathy and it was not seen in non ischemic territory with significant $p$ value of $<0.01$ and odd ratio of 9.09 .
- Transmural myocardial fibrosis in coronary territory was seen in $2(50 \%)$ patients of ischemic cardiomyopathy and not seen in non ischemic cardiomyopathy with significant $P$ value of 0.03 and odd ratio of 1.3.

- The transmural myocardial fibrosis in non coronary territory was not seen in ischemic cardiomyopathy and was seen in $2(12.50 \%)$ patients of non ischemic cardiomyopathy with insignificant $P$ value of 1.0.

- The focal patchy type of myocardial fibrosis was seen in the $1(6.25 \%)$ patients of non ischemic cardiomyopathy and not seen in the ischemic cardiomyopathy with insignificant $P$ value of 1.00 .

- The subendocardial myocardial fibrosis in non coronary territory, midmyocardial fibrosis and epicardial myocardial fibrosis was not seen in either of the ischemic and non ischemic cardiomyopathy. 


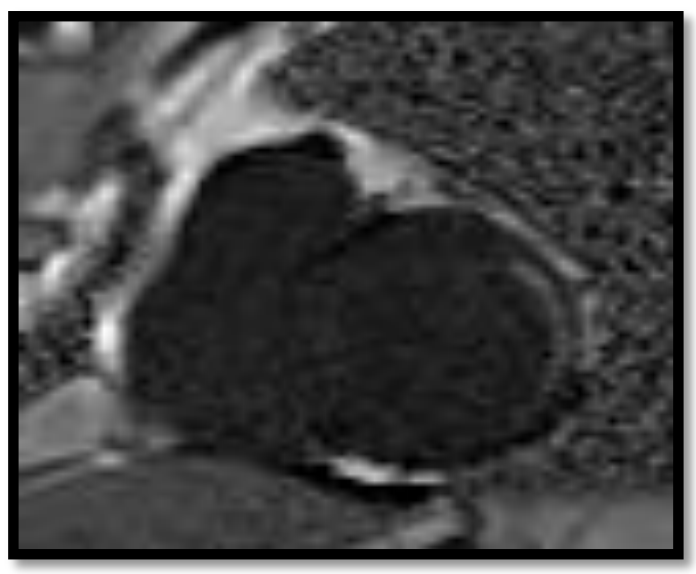

Fig 1(a)

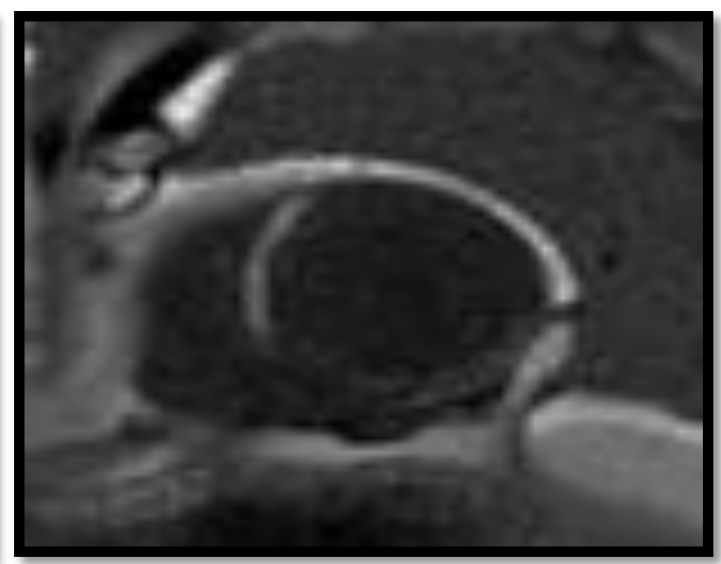

Fig 1(b)

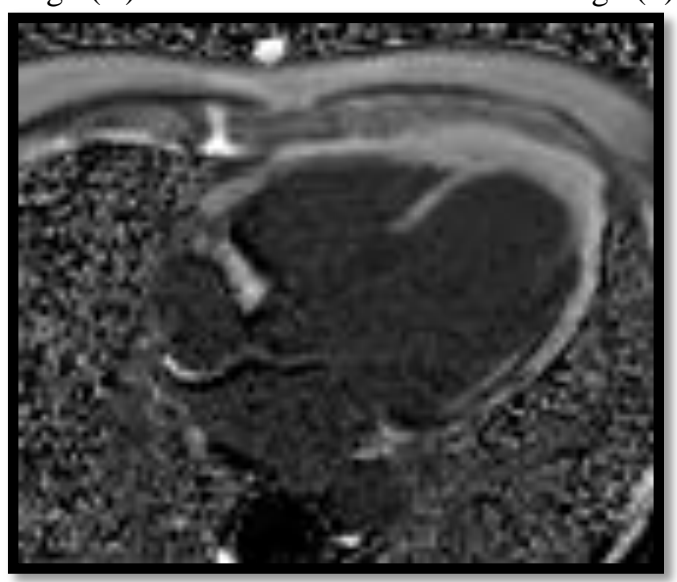

Fig 1(c)

(LAD-Left anterior descending artery, $\mathrm{LCx}$ - Left circumflex artery.)

- Figure 1(a); showing transmural enhancement in LAD territory, fig 1(b); showing sub-endocardial enhancement in LCx territory fig 1(c); showing LAD and LCx territory enhancement in four chamber view.

- A case of ischemic cardiomyopathy of LAD and LCx territory.

$>$ Graphical presentation of pattern of myocardial fibrosis in ischemic and non ischemic cardiomyopathies.

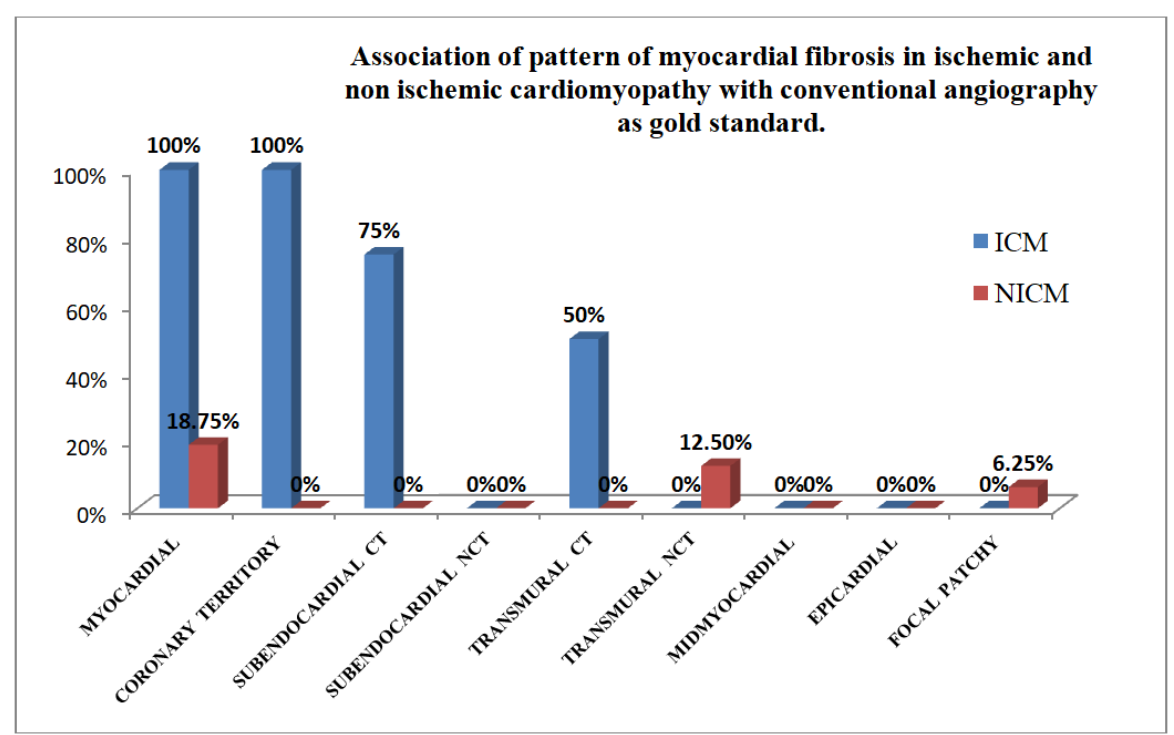

Figure 3: Showing the pattern of myocardial fibrosis in ischemic and non ischemic cardiomyopathy with conventional angiography as gold standard. (CT- Coronary Territory, NCT- Non Coronary Territory) 


\section{Discussion:}

In our study, myocardial fibrosis was seen in $38.8 \%$ patients. The conventional angiography was done in 20 patients and which was considered gold standard for diagnosis of ischemic and non ischemic cardiomyopathy. The pattern of myocardial fibrosis seen in our study was subendocardial in coronary territory, transmural in coronary and non coronary territory, myocardial fibrosis in coronary territory (subendocardial + transmural) and focal patchy type of myocardial fibrosis.

Myocardial fibrosis was seen in $100 \%$ patients with ischemic cardiomyopathy while it was present in $18.75 \%$ patients with non ischemic cardiomyopathy. While in another study by McCrohon et $\mathbf{a l}^{\mathbf{3}}$ (2003), all patients $(100 \%)$ with LV dysfunction and CAD had late gadolinium enhancement, which was subendocardial or transmural while $41 \%$ with DCM of non ischemic type showed late gadolinium enhancement. These finding are in agreement with our study. The reason for low percentage for myocardial fibrosis in non ischemic cardiomyopathy in our study may be due to the small sample size as conventional angiography was done in only 20 patients. In a study done by Hunold et $\mathbf{a l}^{4} \mathbf{( 2 0 0 5 )}$, pattern of LGE in ischemic scar was compared with that of non-ischemic scar and concluded that In MI scar, LE always involves the subendocardial layer. If, LE doesn't involve the subendocardial layer, different nonischemic myocardial diseases have to be considered. This is in agreement with our study as there is association of subendocardial and transmural myocardial fibrosis in coronary territory with ischemic cardiomyopathy in our study which was seen in $100 \%$ of patients.

\section{Conclusion:}

Cardiac MRI has important role in dilated cardiomyopathies for distinguishing ischemic and non ischemic types as well as evaluation of various etiological types.

\section{References;}

1. Maron BJ. The 2006 American Heart Association classification of cardiomyopathies is the gold standard. Circulation: Heart Failure 2008;1:72-76.

2. O'Donnell DH, Abbara S, Chaithiraphan V, Yared K, Killeen RP, Martos R, Keane D, Cury RC, Dodd
JD. Cardiac MR Imaging of Nonischemic Cardiomyopathies: Imaging Protocols and Spectra of Appearances. RSNA 2012; 262(2).

3. McCrohon JA, Moon JC, Prasad SK, McKenna WJ, Lorenz CH, Coats AJ, Pennell DJ. Differentiation of heart failure related to dilated cardiomyopathy and coronary artery disease using gadolinium-enhanced cardiovascular magnetic resonance. Circulation 2003; 108:54-59.

4. Hunold P, Schlosser T, Vogt FM, Eggebrecht H, Schmermund A, Bruder O, Schüler WO, Barkhausen J. Myocardial late enhancement in contrast-enhanced cardiac MRI: distinction between infarction scar and non-infarction-related disease. American Journal of Roentgenology 2005; 184:1420-6.

5. McKenna WJ, Maron BJ, Thiene G. Classification, Epidemiology, and Global Burden of Cardiomyopathies. The AHA 2017;121:722-730.

6. Al-Mallah MH, Shareef MN. The role of cardiac magnetic resonance imaging in the assessment of non-ischemic cardiomyopathy. Heart failure reviews 2011; 16:369-380.

7. Bellenger NG, Francis JM, Davies CL, Coats AJ, Pennell DJ. Establishment and performance of a magnetic resonance cardiac function clinic. Journal of cardiovascular magnetic resonance 2000; 2:15-22.

8. Jackson E, Bellenger N, Seddon M, Harden S, Peebles C. Ischaemic and non-ischaemic cardiomyopathies - cardiac MRI appearances with delayed enhancement. Clinical radiology 2007; 62:395-403.

9. Hergan K, Schuster A, Mair M, Burger R, Töpker M. Normal cardiac diameters in cine-MRI of the heart. RoFo: Fortschritte auf dem Gebiete der Rontgenstrahlen und der Nuklearmedizin 2004; 176:1599-606.

10. Wong TC, Piehler K, Puntil KS, Moguillansky D, Meier CG, Lacomis JM, Kellman P, Cook SC, Schwartzman DS, Simon MA, Mulukutla SR. Effectiveness of late gadolinium enhancement to improve outcomes prediction in patients referred for cardiovascular magnetic resonance after echocardiography. Journal of Cardiovascular Magnetic Resonance 2013; 15:6. 